Note: This is a preprint of a paper being submitted for publication. Contents of this paper should not be quoted nor referred to without permission of the author(s).

\title{
Pulsed-laser deposition of electronic oxides: superconductor and semiconductor applications
}

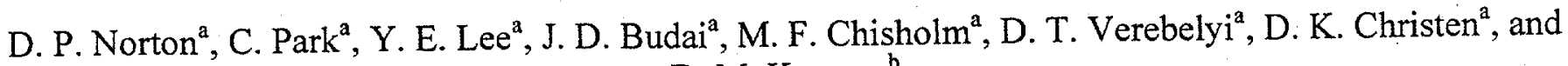 \\ D. M. Kroeger ${ }^{\mathrm{b}}$ \\ ${ }^{a}$ Solid State Division, Oak Ridge National Laboratory, Oak Ridge, TN 37831-6056 \\ ${ }^{b}$ Metals and Ceramic Division, Oak Ridge National Laboratory
}

Submitted to:

Proceedings of the SPIE Vol. 3933

Conference on Laser Applications in Microelectronic and Optoelectronic Manufacturing V

San Jose, CA

January $24-26,2000$

\begin{abstract}
"The submitted manuscript has been authored by a contractor of the U.S. The submilled manucript has boen authorod 2464 . Accordingly, the

Government under contract DE-ACOS-960R22464. Accordingly, the

U.S. Government retains a nonexclusive, royalty-free license to pubiish or

reproduce the published form of this contribution, or allow others to do so
for U.S. Govermment purposes."
\end{abstract}

December 1999

\author{
Prepared by \\ Solid State Division \\ Oak Ridge National Laboratory \\ P.O. Box 2008 \\ Oak Ridge, Tennessee 37831-6056 \\ managed by \\ LOCKHEED MARTIN ENERGY RESEARCH CORP. \\ for the \\ U.S. DEPARTMENT OF ENERGY \\ under contract DE-AC05-96OR22464
}




\title{
Pulsed-laser deposition of electronic oxides: superconductor and semiconductor applications
}

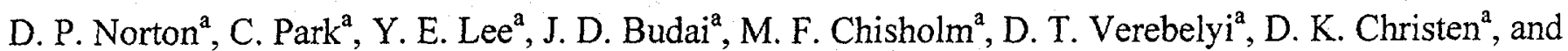 \\ D. M. Kroeger ${ }^{b}$ \\ ${ }^{a}$ Solid State Division, Oak Ridge National Laboratory, Oak Ridge, TN 37831-6056 \\ ${ }^{b}$ Metals and Ceramic Division, Oak Ridge National Laboratory
}

\begin{abstract}
Over the past decade, pulsed-laser deposition (PLD) has proven to be one of the most versatile and effective methods for obtaining high-quality electronic oxide thin-film materials. Much of this success can be attributed to its initial use in depositing high temperature superconducting materials. However, pulsed-laser deposition is now a leading research tool in the development of various electronic oxide thin-film technologies. In this paper, recent progress in the deposition of oxide materials on dissimilar materials for both superconductor and semiconductor applications is discussed. Recent developments in the synthesis of superconducting wires via epitaxial growth of superconducting oxides on biaxially textured metal tapes is described. In addition, efforts to integrate high-k dielectric oxides on semiconductor surfaces using pulsed-laser deposition are highlighted.
\end{abstract}

Keywords: Pulsed-laser deposition, electronic oxides, superconductor, dielectric, dissimilar epitaxy, epitaxial growth

\section{INTRODUCTION}

In the epitaxial growth of oxide materials, pulsed laser deposition continues to excel as a highly effective method for obtaining high-quality crystalline films. One of the more interesting materials challenges in electronic oxides is that of dissimilar epitaxy on non-oxide substrates. The synthesis and properties of crystalline ionic oxide films on metallic or covalent substrates is important for many applications, as single crystal oxides are rarely the substrate of choice. Two examples involving dissimilar oxide epitaxy are described in this paper: superconducting films on metals for coated conductors and dielectrics on semiconductors for MOSFET devices.

\section{SUPERCONDUCTING OXIDES ON METAL TAPES FOR CONDUCTORS}

Significant effort to develop a high temperature superconducting (HTS) wire or tape has focused on the epitaxial growth of superconducting films on biaxially textured metals. ${ }^{, 2}$ This approach, illustrated in Fig. 1, is dependent on the heteroepitaxial growth of oxide buffer layer films on metal surfaces. In order to realize an HTS film possessing a high critical current on a biaxially textured metal substrate, the buffer layer architecture must satisfy a set of rather stringent requirements. The buffer layer construct must be chemically compatible with both the metal and superconductor. It must be mechanically robust so as to prevent microcrack formation at the HTS/buffer layer interface. It must also be epitaxial relative to the biaxially textured metal with a singular (001) orientation. The latter requirement is particularly challenging as the epitaxy of metal oxides on metal surfaces is determined not only by the relative lattice match

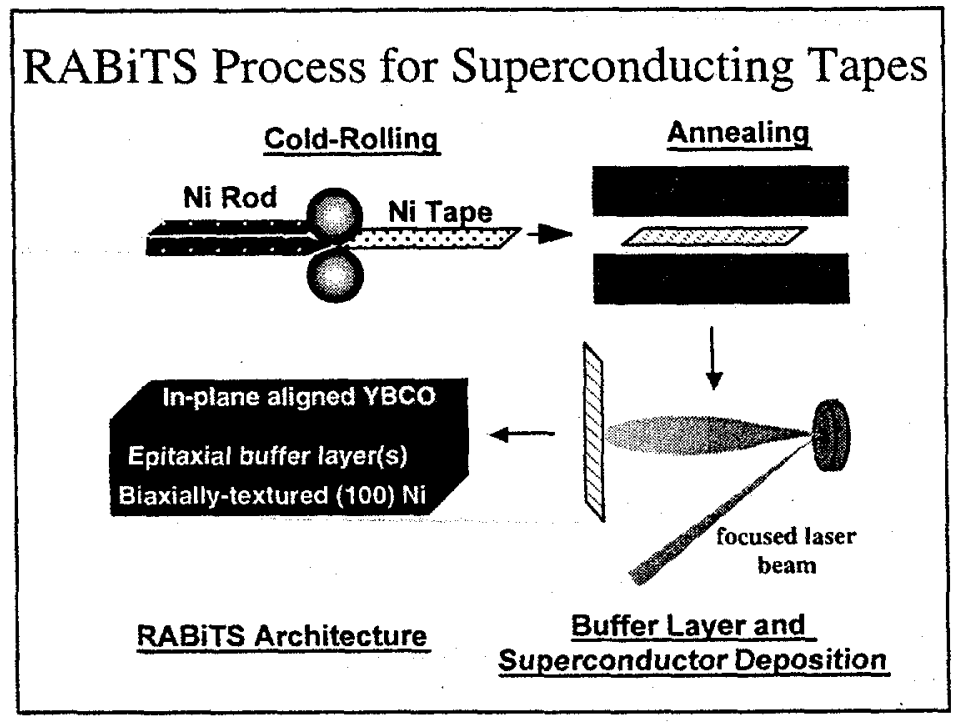

Figure 1 Schematic of Rolling Assisted Biaxially Textured Substrate (RABiTS) approach to coated conductor development. 


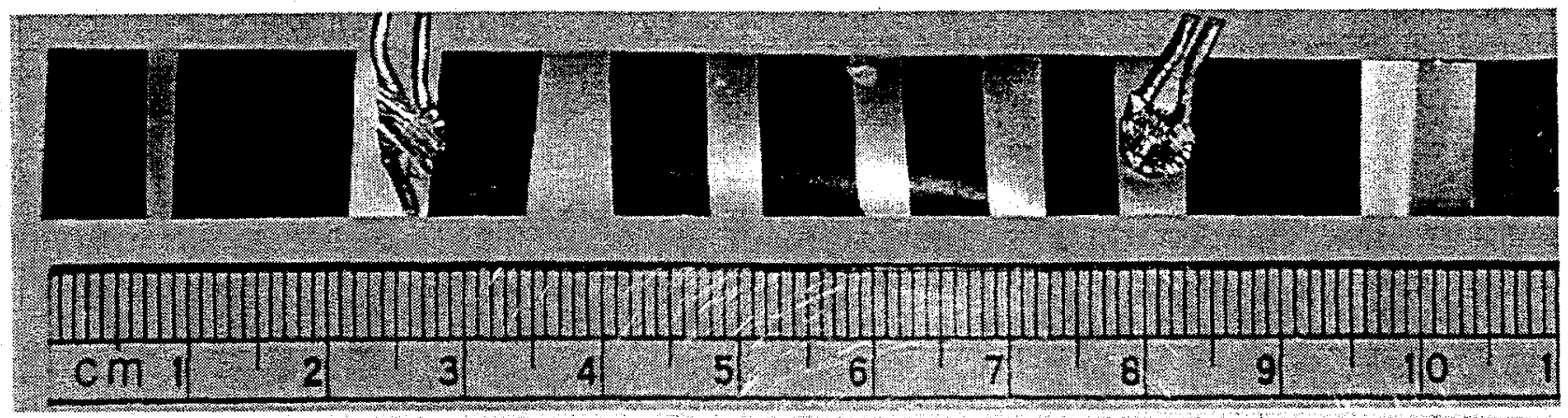

Figure 2 Photograph of $10 \mathrm{~cm}$ long $\mathrm{YBCO} / \mathrm{CeO}_{2} / \mathrm{YSZ} / \mathrm{CeO}_{2} / \mathrm{Ni}$ tape

between film and substrate, but by possible roles of a native oxide layer and/or intermetallic phases formed during film nucleation.

Previous efforts have satisfied these requirements with multilayer combinations of various oxide buffer layers. Superconducting films with critical current densities in excess of $1 \mathrm{MA} / \mathrm{cm}^{2}$ at $77 \mathrm{~K}$ have been achieved for epitaxial $\mathrm{YBa}_{2} \mathrm{Cu}_{3} \mathrm{O}_{7}$ films on rolled-textured Ni substrates with the use of certain epitaxial buffer-layer constructs. ${ }^{3}$ For example, PLD has been used to nucleate an epitaxial (001)-oriented $\mathrm{CeO}_{2}$ layer on a biaxially textured $(001) \mathrm{Ni}$ surface. ${ }^{4} \mathrm{~A}$ tendency for the $\mathrm{CeO}_{2}$ layer to crack due to differences in thermal expansion coefficients of the oxide film and metal tape requires an additional epitaxial yttria-stabilized zirconia (YSZ) buffer layer on the $\mathrm{CeO}_{2}$ in order to achieve crack-free superconducting films. ${ }^{1}$ In this case, the superior mechanical properties of the YSZ layer circumvent the cracking problem, and enable the formation of superconducting films with high critical currents. A $10 \mathrm{~cm}$ long $\mathrm{YBCO} / \mathrm{CeO}_{2} \mathrm{YSZ} / \mathrm{CeO}_{2} / \mathrm{Ni}$ superconductivity tape is shown in Fig. 2.

Though effective in forming a high current superconducting tape, the use of a multilayer buffer architecture introduces significant complexity to the fabrication process. Ideally, one would prefer to use a single buffer layer. One of the most attractive materials for a single buffer layer that is mechanically robust and chemically inert is YSZ. 5 . Unfortunately, previous efforts to grow epitaxial YSZ films with a single (001) orientation directly on rolled-textured (001) Ni tapes have been unsuccessful, with a mixture of $(100)$ and (111) orientation realized. We have recently investigated the nucleation and growth of epitaxial (001) YSZ on the (001) Ni surface using pulsed-laser deposition. Nucleation on an oxide-free $(001)$ biaxially-textured $\mathrm{Ni}$ surface yields a mixed (111) and (001)-oriented film. However, (001)-oriented epitaxy is achieved by nucleating the YSZ film on a surface that is apparently oxygen terminated. Exposing the surface to conditions where significant $\mathrm{NiO}$ forms results in the nucleation of polycrystalline material. Using the (001)-oriented $\mathrm{YSZ}$ as a template, a $\mathrm{YBa}_{2} \mathrm{Cu}_{3} \mathrm{O}_{7} / \mathrm{YSZ} /$ biaxially-textured $\mathrm{Ni}$ structure with a high $\mathrm{J}_{\mathrm{c}}$ is realized.

The substrates used in this study were biaxially-textured (001) $\mathrm{Ni}$ tapes (50 $\mathrm{mm}$ thick) produced by cold-rolling and annealing. ${ }^{8}$ The starting purity of the Ni tape was $99.99 \%$. For texture development, the cold-rolled metal tape was enclosed in a tantalum envelope and annealed in vacuum with a base pressure of $2 \times 10^{-6}$ Torr at $800-1000^{\circ} \mathrm{C}$ for 60 minutes. The tantalum envelope serves as a local oxygen getter during the anneal. The degree of in-plane and out-of-plane texture for the substrates as determined by $\mathrm{x}$-ray diffraction (XRD) rocking curves was approximately $8^{\circ}$. After annealing, the $\mathrm{Ni}$ tape was stored in air until mounted on a heater block using $\mathrm{Ag}$ paint and loaded into an o-ring sealed vacuum chamber for pulsedlaser deposition. Note that exposure to air almost immediately oxidizes the nickel surface. A 10 mol.\% yttria-stabilized $\mathrm{ZrO}_{2}$ ceramic target was used to deposit the YSZ film. A KrF excimer laser beam was incident on the rotating target surface at an angle of $45^{\circ}$. The laser energy density was $2.6 \mathrm{~J} / \mathrm{cm}^{2}$ with a deposition rate of $0.25 \mathrm{~nm} / \mathrm{sec}$. The target-to-substrate distance was $7 \mathrm{~cm}$. The base pressure of the growth chamber was $10^{-6}$ Torr, assumed to consist primarily of water vapor. The YSZ nucleation experiments were performed in the temperature range of $600-800^{\circ} \mathrm{C}$.

For the experiments reported here, an initial nucleation layer $(\sim 5 \mathrm{~nm})$ of YSZ was deposited under various conditions, followed by the additional epitaxial growth of a $200 \mathrm{~nm}$ thick YSZ film with $\mathrm{P}\left(\mathrm{O}_{2}\right)=10^{-4}$ Torr. The relatively thick epitaxial film grown on the nucleated template layer effectively reflects the crystalline orientation of the nucleated layer. Three 

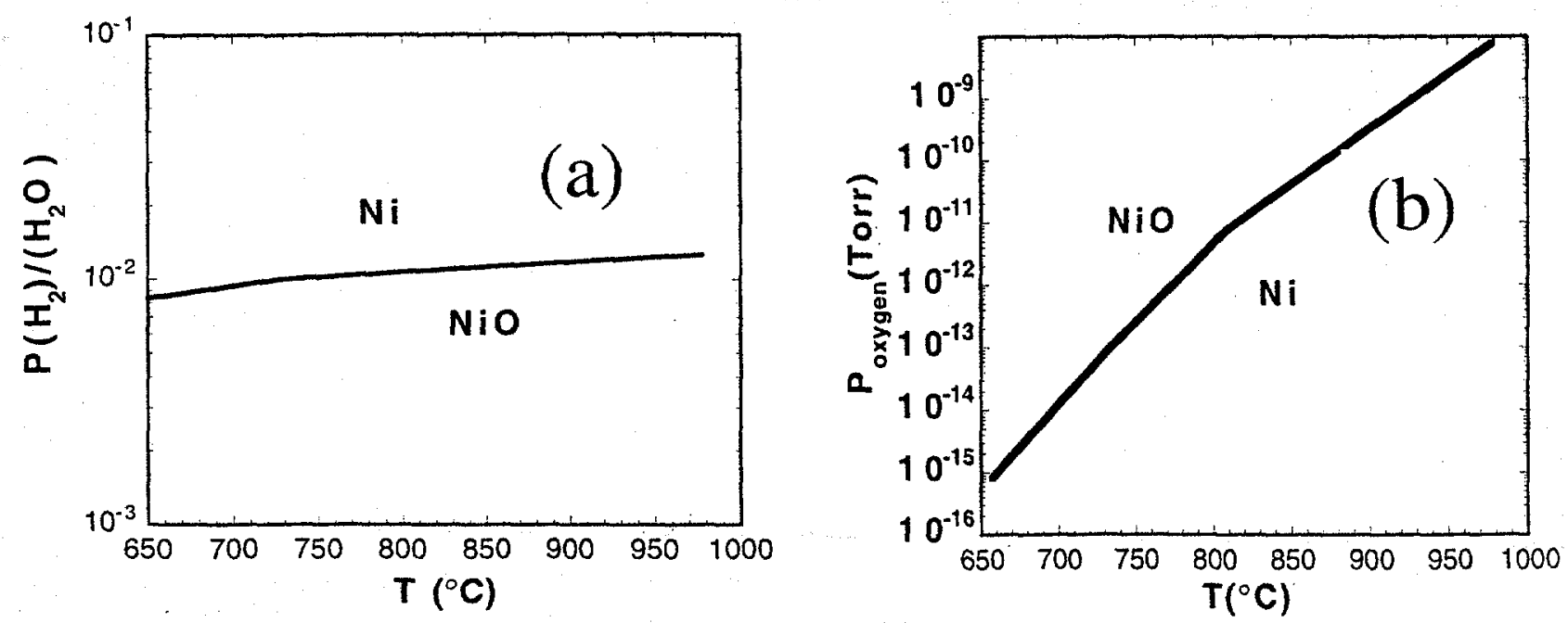

Figure $3 \mathrm{NiO}$ stability curves in the presence of hydrogen (a) and oxygen (b).

ambient conditions were considered during nucleation. First, nucleation was carried out on an oxide-free surface by introducing sufficient hydrogen partial pressure (up to $200 \mathrm{mTorr} 4 \% \mathrm{H}_{2} / 96 \%$ Ar mixture) so as to reduce any $\mathrm{NiO}$ on the $\mathrm{Ni}$ surface as determined from the thermodynamics of $\mathrm{NiO}$ reduction (case A). Figure 3a) shows the stability curve for NiO in the presence of hydrogen and water vapor. ${ }^{9}$ For $\mathrm{P}\left(\mathrm{H}_{2}\right) / \mathrm{P}\left(\mathrm{H}_{2} \mathrm{O}\right)>10^{-2}$ at $\mathrm{T}>600^{\circ} \mathrm{C}$, NiO will be reduced, yielding an oxide-free surface. Second, nucleation was performed under base pressure conditions (case B). For a vacuum system with a base pressure of $\sim 10^{-6}$ Torr, the residual oxygen pressure will be at least $10^{-8}$ Torr. Using Ellingham diagrams for binary oxides, the equilibrium oxygen partial pressure for $\mathrm{NiO}$ heated to $600-800^{\circ} \mathrm{C}$ should be in the range of $10^{-16}$ to $10^{-11}$ Torr as illustrated in Fig. 3b. ${ }^{9}$ Under the above conditions, oxygen termination of the surface would be expected. Lastly, nucleation was carried out in an oxygen partial pressure of $5 \times 10^{-6}$ Torr or greater (case C). Under these conditions, significant NiO coverage of the Ni surface is expected.

For nucleation of YSZ in the presence of sufficient hydrogen to yield an oxide-free nickel surface (case A), polycrystalline films with mixed orientation were realized. This differs from the case for $\mathrm{CeO}_{2}$, where (001) epitaxy is achieved via nucleation on an oxide-free nickel surface. ${ }^{1}$ One possible explanation for this difference in $\mathrm{CeO}_{2}$ and $\mathrm{YSZ}$ nucleation resides in the different cation chemistry. Ce can exist in either +4 or +3 valence, while $\mathrm{Zr}$ is a monovalent +4 . Within the cubic fluorite structure, $\mathrm{CeO}_{2 \cdot x}$ can accommodate significant oxygen deficiency, while $\mathrm{YSZ}$ can not for a given cation composition. The excess $\mathrm{Zr}$ may react with the nickel surface forming intermetallic compounds that interfere with (001) epitaxy. Additional work needs to be performed to address this issue.

In contrast to nucleation in the presence of hydrogen, nucleation of YSZ at a base pressure of $10^{-6}$ Torr (case B) results in a singular (001) epitaxial relationship. X-ray diffraction $\theta-2 \theta$ scans along the surface normal for an epitaxial (001) YSZ film that was nucleated on the $\mathrm{Ni}(001)$ substrate at $800^{\circ} \mathrm{C}$ in a background pressure of $2 \times 10^{-6}$ Torr with no intentional oxygen or hydrogen flow shows that the film is essentially $100 \%(001)$ oriented with an intensity ratio of the (111) to (200) peaks less than 0.01 . $\omega$-scans and $\phi$-scans of the YSZ peaks indicate that the film is in-plane aligned and epitaxial with respect to the biaxially textured $\mathrm{Ni}$ substrate. The in-plane and out-of-plane mosaic spread for the film is slightly smaller than that measured for the substrate. Similar results were obtained for films deposited at temperatures as low as $600^{\circ} \mathrm{C}$. For the case where an oxygen partial pressure greater than $5 \times 10^{-6}$ Torr is introduced during either substrate heating or film nucleation (case C), a significant or dominant YSZ (111) oriented component was evident in the $x$-ray diffraction data. An oxygen partial pressure of $10^{-5}$ Torr or greater during nucleation yields nearly $100 \%$ (111)-oriented YSZ.

With the epitaxial growth of high-quality YSZ on biaxially textured nickel, a single buffer layer architecture for the growth of $\mathrm{YBa}_{2} \mathrm{Cu}_{3} \mathrm{O}_{7}$ becomes possible. A $0.25 \mathrm{~nm}$ thick $\mathrm{YBa}_{2} \mathrm{Cu}_{3} \mathrm{O}_{7}$ film was deposited on the $250 \mathrm{~nm} \mathrm{YSZ}$ layer at a deposition temperature of $750^{\circ} \mathrm{C}$ and oxygen pressure of $200 \mathrm{~m}$ Torr. A $\theta-2 \theta$ XRD scan along the surface normal for the $\mathrm{YBa}_{2} \mathrm{Cu}_{3} \mathrm{O}_{7} /$ YSZ / Ni structure shows only c-axis oriented $\mathrm{YBa}_{2} \mathrm{Cu}_{3} \mathrm{O}_{7}$, with the intensity ratio of the $\mathrm{YSZ}(111)$ to (200) peaks less than 0.02. X-ray diffraction $\omega$-scans and $\phi$-scans for the $\mathrm{YSZ}$ and $\mathrm{YBa}_{2} \mathrm{Cu}_{3} \mathrm{O}_{7}$ peaks show that the layers are in-plane aligned and epitaxial with respect to the biaxially textured $\mathrm{Ni}$ substrate. The in-plane and out-of-plane mosaic spreads for the 
$\mathrm{YBa}_{2} \mathrm{Cu}_{3} \mathrm{O}_{7}$ and $\mathrm{YSZ}$ layers are similar to that measured for the metal tape. Scanning electron microscopy images of the (001) YSZ/Ni films show no evidence for microcracking in the YSZ layer. The critical current density at $77 \mathrm{~K}$ for the $\mathrm{YBa}_{2} \mathrm{Cu}_{3} \mathrm{O}_{7}$ film was as high as $1 \mathrm{MA} / \mathrm{cm}^{2}$, which is the highest reported value for any epitaxial $\mathrm{YBa}_{2} \mathrm{Cu}_{3} \mathrm{O}_{7}$ film on biaxially-textured metal substrate with a single buffer layer separating the superconductor from the biaxially textured metal substrate.

\section{HIGH-K DIELECTRICS ON SEMICONDUCTORS FOR MOSFET DEVICES}

Another interesting case of dissimilar epitaxy involving oxides is the growth on semiconductors. Metal/oxide/semiconductor (MOS) structures are key elements in microelectronic applications. ${ }^{10,11}$ Various semiconductor materials would be attractive for MOS-type device applications given a method to form well-defined oxide/semiconductor interfaces suitable for functional structures. For example, Ge and SiGe alloys are attractive semiconductor materials for electronic applications, possessing higher carrier mobilities and thermal conductivities than that of silicon. Germanium possesses a simple cubic crystal structure with $\mu_{\mathrm{n}}=3900 \mathrm{~cm}^{2} / \mathrm{V}-\mathrm{sec}, \mu_{\mathrm{p}}=1800 \mathrm{~cm}^{2} / \mathrm{V}-\mathrm{sec}$, and a thermal conductivity of $0.6 \mathrm{~W} / \mathrm{cm}-\mathrm{K}$. Unfortunately, the native germanium oxides are not suitable for MOS-type device structures. ${ }^{12,13}$ The formation of stable metal oxides on Ge could prove instrumental in the development of Ge and/or SiGe alloy integrated circuits. For applications involving sensors, photovoltaics, and optoelectronics, the formation of well-defined metal oxide/semiconductor interfaces for semiconductor materials other than silicon is vital to current and future device architectures. In many cases, one would prefer to have a welldefined metal oxide/semiconductor structure devoid of any native oxide at the interface, as the presence of native oxide at the interface limits the performance of these structures. This has been demonstrated for the case of silicon, in which molecular beam epitaxy was used to grow a crystalline oxide as a monolithic, commensurate structure on silicon.[5] In addition, a method to form oxides that are epitaxial on semiconductors would enable the integration of various epitaxial oxide materials and device structures with semiconductor electronics by providing a crystalline oxide template for additional epitaxial oxide film growth.

We have recently explored the epitaxial growth and properties of $\mathrm{CeO}_{2}$ on $(001) \mathrm{Ge}$ using pulsed-laser deposition. Hydrogen is introduced as a background gas during the film nucleation in order to eliminate the native $\mathrm{GeO}_{2}$ on the $\mathrm{Ge}$ surface and achieve epitaxy.,15 The use of hydrogen greatly relaxes vacuum requirements needed for the formation of a $\mathrm{GeO}_{2}-\mathrm{free}^{1}$ surface. Using this approach, (001)-oriented $\mathrm{CeO}_{2}$ thin films were obtained on the (001) Ge surface. The resulting metal oxide/semiconductor interface is atomically abrupt, with no apparent native oxide present at the semiconductor /metal oxide interface. These results differ from that observed for $\mathrm{CeO}_{2}$ on $(001) \mathrm{Si}$, where the film is (110)-oriented with significant $\mathrm{SiO}_{2}$ formation at the film/substrate interface. ${ }^{16-18}$

The deposition of (001) epitaxial cerium oxide on single crystal Ge (001) was performed by pulsed-laser deposition using a $\mathrm{KrF}$ excimer laser. Single crystal $(001) \mathrm{Ge}$ substrates were cleaned by successive rinsing in trichloroethylene, acetone, and methanol, followed by rinsing in deionized water. The native oxide was then removed by a $30 \mathrm{sec}$ dipping in a 1:10 $\mathrm{HF}: \mathrm{H}_{2} \mathrm{O}$ solution. The substrate was blown dry with dry nitrogen and mounted on the heater platen using silver paint. The sample was loaded into the vacuum chamber for pulsed-laser deposition of the oxide film. The chamber was evacuated to an initial base pressure that ranged from $5 \times 10^{-6}$ Torr to $2 \times 10^{-9}$ Torr. The mounted Ge substrate was annealed in vacuum at $350^{\circ} \mathrm{C}$ for 2-12 hrs in order to decompose the organic binder in the silver paint. Prior to heating, the ablation target was in situ cleaned by laser ablation with a shutter between the substrates and ablation target.

In order to minimize or eliminate any native germanium oxide on the substrate surface prior to growth, hydrogen gas was introduced into the chamber to a sufficient pressure such that the ratio of hydrogen to water vapor partial pressure $\mathrm{P}\left(\mathrm{H}_{2}\right) /$ $\left(\mathrm{P}\left(\mathrm{H}_{2} \mathrm{O}\right)\right.$ was approximately at or above the $\mathrm{GeO}_{2}$ stability curve at the anticipated oxide film growth temperature as shown in Fig. 4. This curve was derived from Ellingham diagrams for oxide materials. ${ }^{9.19}$ The oxide stability line can be estimated from the temperature-dependent Gibbs free energy of the chosen native oxide when compared to the $\mathrm{H}_{2} \mathrm{O} / \mathrm{H}_{2}$ equilibrium behavior. Depending on the anticipated metal oxide deposition temperature, the $\mathrm{GeO}_{2}$ instability criterion translates into a value of $\mathrm{P}\left(\mathrm{H}_{2}\right) / \mathrm{P}\left(\mathrm{H}_{2} \mathrm{O}\right)>0.04$, preferably greater than 1.0. As a practical matter, the base pressure of the vacuum systems consists mostly of $\mathrm{H}_{2} \mathrm{O}$.

For the experiments reported here, a flow of $4 \% \mathrm{H}_{2} / 96 \%$ Ar was introduced into the chamber with the $\mathrm{H}_{2} / \mathrm{Ar}$ pressure ranging from $10^{-5}$ to $10^{-1}$ Torr, depending on the base pressure. For example, an $\mathrm{H}_{2} / \mathrm{Ar}$ pressure of 0.1 Torr yields a hydrogen partial pressure of $4 \times 10^{-3}$ Torr, and a value of $\mathrm{P}\left(\mathrm{H}_{2}\right) / \mathrm{P}\left(\mathrm{H}_{2} \mathrm{O}\right)$ of $8 \times 10^{2}$ for a base pressure of $5 \times 10^{-6}$ Torr. The substrate was then heated to the growth temperature in the $4 \% \mathrm{H}_{2} / 96 \% \mathrm{Ar}$ background. As the substrate is heated, the hydrogen reduces 
any $\mathrm{GeO}_{2}$ that resides or forms on the substrate surface, resulting in the gas-phase etching of the native oxide. The final growth temperature must be consistent with the requirement that the conditions (temperature, water vapor partial pressure, hydrogen partial pressure) be above the $\mathrm{GeO}_{2}$ stability line where the formation of $\mathrm{GeO}_{2}$ is thermodynamically unfavored. Under these conditions, a metal oxide material that is stable for the chosen temperature/water vapor/hydrogen conditions can be deposited onto the heated substrate by means of pulsed-laser deposition. This oxide material should be thermodynamically stable in contact with $\mathrm{Ge}^{20}$ Cerium oxide satisfies this criterion,

After heating to the selected growth temperature, a $\mathrm{CeO}_{2}$ film was deposited on the $\mathrm{Ge}$ surface. The $\mathrm{KrF}$ excimer laser energy density was $\sim 1.5 \mathrm{~J} / \mathrm{cm}^{2}$ with a laser repetition rate of $1 \mathrm{~Hz}$. These conditions yielded a deposition rate of $\sim 0.1 \mathrm{~nm} /$ laser pulse when using a pressed and sintered $\mathrm{CeO}_{2}$ ablation target. Both the metal cation and oxygen atoms are provided by laser ablation as short, discreet pulses. Between the laser pulses, the metal oxide / semiconductor system can relax to the conditions that thermodynamically favor instability of the native oxides. After the initial film nucleation, additional $\mathrm{CeO}_{2}$ could be deposited on the initial oxide film template using deposition conditions that do not necessarily coincide with the requirements of $\mathrm{GeO}_{2}$ thermodynamic instability as outlined for the template oxide layer, thus allowing the $\mathrm{CeO}_{2}$ stoichiometry to be controlled. After film growth, the germanium substrate was typically cooled in vacuum.

Figure 5 shows x-ray diffraction data for a $50 \mathrm{~nm}$ thick $\mathrm{CeO}_{2}$ film on (001) Ge grown at $750^{\circ} \mathrm{C}$. $\mathrm{The} \mathrm{CeO} 2$ film was deposited with $\mathrm{P}\left(\mathrm{H}_{2}\right)=4 \times 10^{-7}$ Torr and a base pressure $=2 \times 10^{-9}$ Torr. Approximately $5 \mathrm{~nm}$ was deposited in the presence of hydrogen. The remaining $45 \mathrm{~nm}$ of $\mathrm{CeO}_{2}$ was deposited with no hydrogen flow. Note that for temperatures greater than
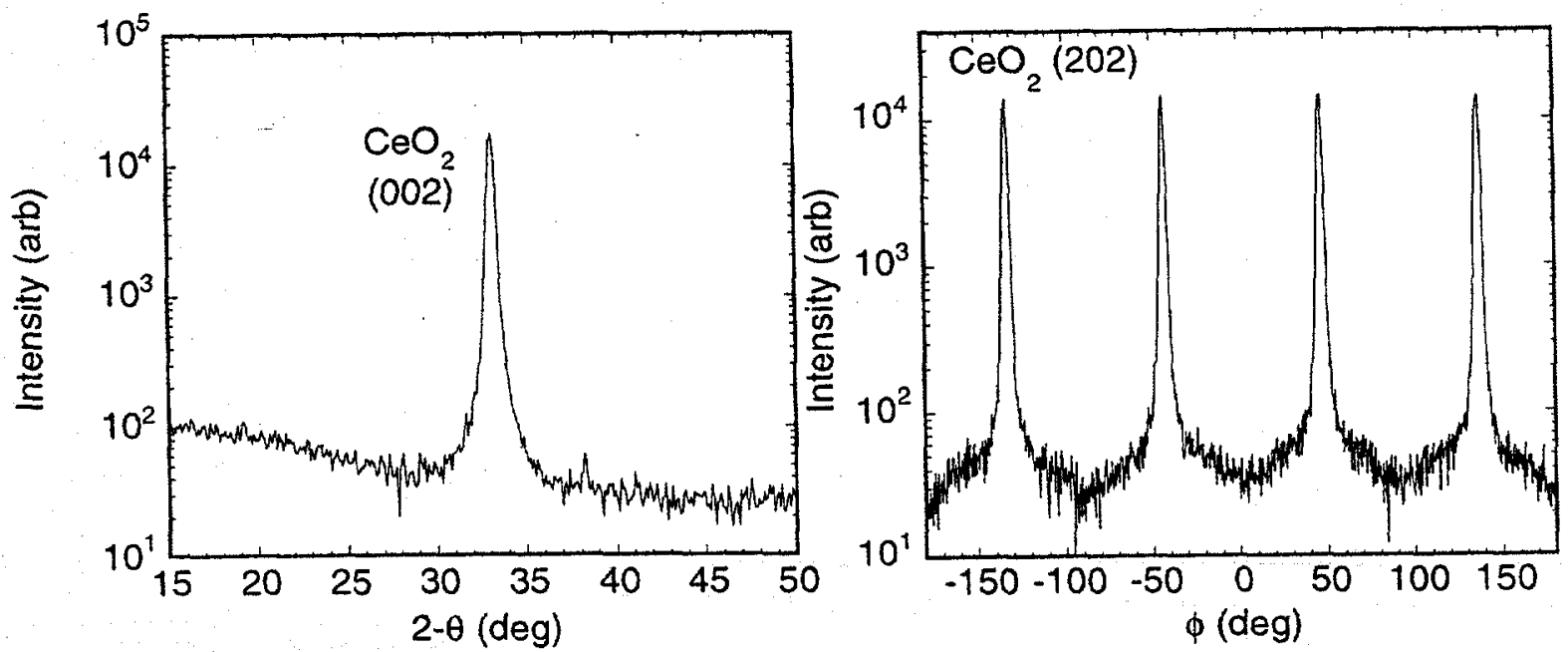

Figure $5 \mathrm{X}$-ray diffraction $2-\theta$ and $\phi$-scans of $\mathrm{CeO}_{2}$ on (001) Ge.

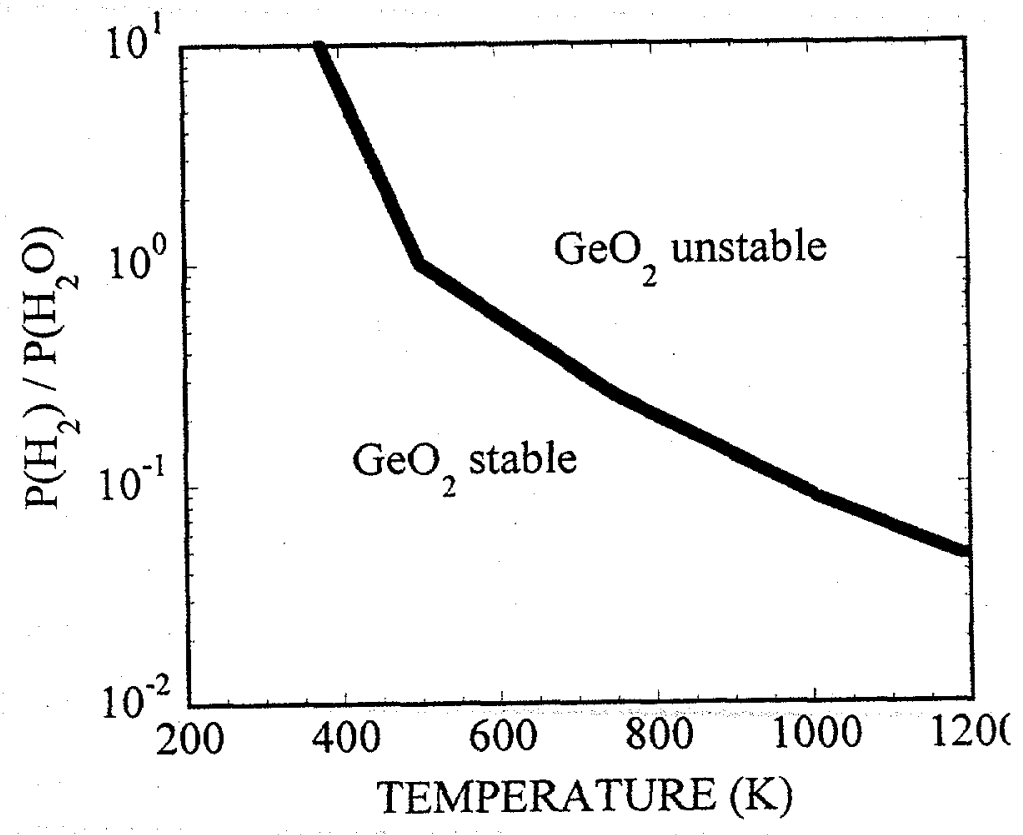

Figure 4. Plot showing $\mathrm{GeO}_{2}$ stability line with respect to the ratio of hydrogen gas to water vapor. The conditions for which $\mathrm{GeO}_{2}$ is unstable are explicitly denoted. 


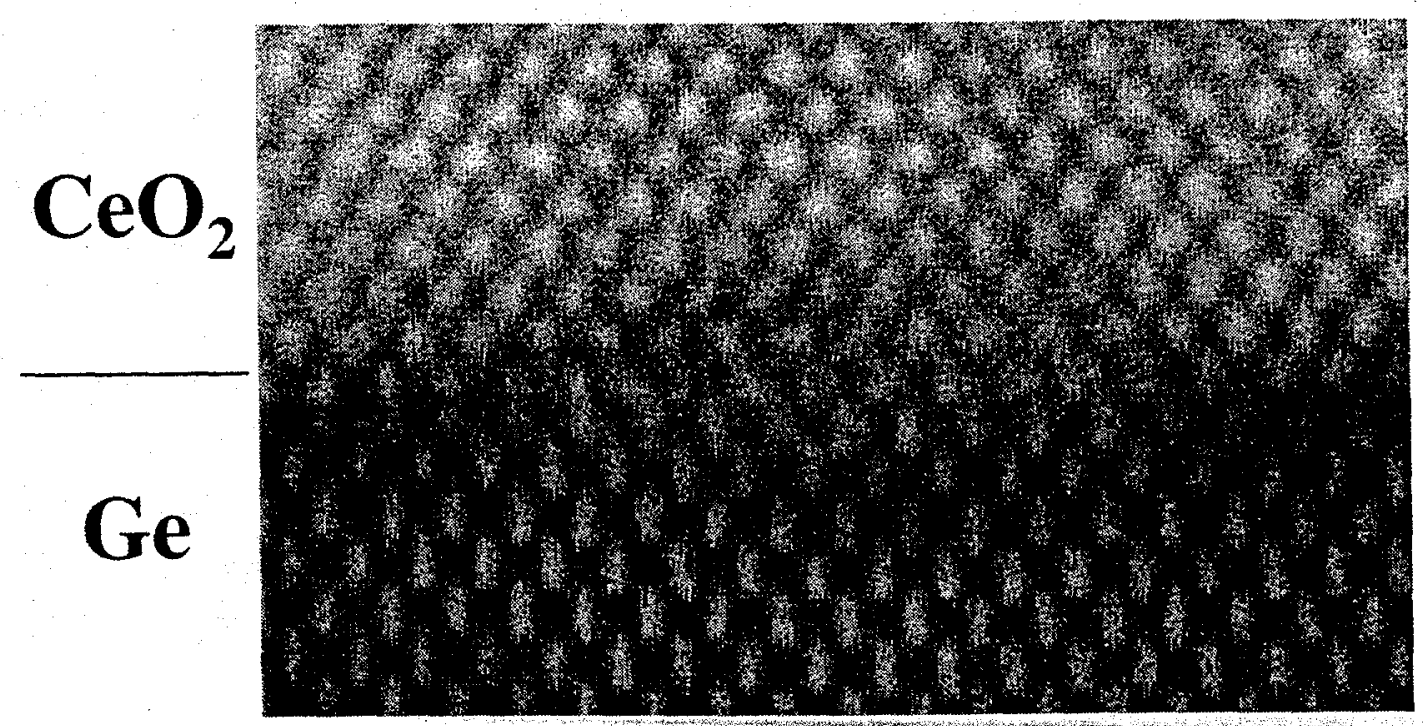

Figure $6 \mathrm{Z}$-contrast STEM image of epitaxial $\mathrm{CeO}_{2} / \mathrm{Ge}$ interface.

$550^{\circ} \mathrm{C}$, only the $(001)$ orientation is observed. In-plane XRD scans confirm that the $\mathrm{CeO}_{2}$ films are in-plane aligned. Note that some broadening in $2 \theta$ is observed at the lower growth temperature, indicating that strain is present in the film.

In addition to $\mathrm{x}$-ray diffraction, the properties of the $\mathrm{CeO}_{2} / \mathrm{Ge}$ interface were investigated using high-resolution scanning transmission electron microscopy (STEM). Cross-section images reveal that $\mathrm{CeO}_{2}$ films deposited at $750^{\circ} \mathrm{C}$ possesses a $3 \mathrm{D}$ island-like morphology that is faceted, with extended defects (pinholes) extending to the substrate at some of the faceted boundaries. Disruption of the $\mathrm{CeO}_{2} / \mathrm{Ge}$ interface in the form of etched holes or amorphous material was evident in the proximity of these defects. Between the defects, the $\mathrm{CeO}_{2} / \mathrm{Ge}$ interface is atomically abrupt and free of $\mathrm{GeO}$. At slightly lower temperatures, faceting is significantly diminished. Figure 6 shows a cross-section Z-contrast STEM image of a $\mathrm{CeO}_{2}$ film that was grown at $650^{\circ} \mathrm{C}$. The absence of an amorphous native oxide layer at the interface differs from that observed for $\mathrm{CeO}_{2}$ films on $\mathrm{Si}$, where significant $\mathrm{SiO}_{2}$ is observed at the film/substrate interface. The fact that $\mathrm{GeO}_{2}$ is thermodynamically less stable than $\mathrm{SiO}_{2}$ suggests that the formation of $\mathrm{GeO}_{2}$ at the interface should be less likely.

\section{CONCLUSIONS}

In conclusion, we have investigated the heteroepitaxial growth of oxides on dissimilar substrates using pulsed-laser deposition. In the nucleation of epitaxial YSZ directly on biaxially-textured (001) Ni tapes using pulsed-laser deposition, the orientation of YSZ depends on the initial state of the substrate, with (001) epitaxy possible by nucleation on an oxygenterminated metal surface. The epitaxial (001) YSZ layer grown on the Ni (001) surface can be used as a single buffer layer for a high temperature superconducting coated conductor architecture, yielding superconducting $\mathrm{YBa}_{2} \mathrm{Cu}_{3} \mathrm{O}_{7}$ films with high critical current densities. In addition, the growth of $(001)$ epitaxial $\mathrm{CeO}_{2}$ on a (001) Ge surface using pulsed-laser deposition in a hydrogen ambient has been realized. By using hydrogen to eliminate $\mathrm{GeO}_{2}$ from the surface during film nucleation, a $\mathrm{CeO}_{2} / \mathrm{Ge}$ interface that is essentially free of $\mathrm{GeO}_{2}$ can be formed. The use of hydrogen to promote the epitaxial growth of oxides on semiconductor surfaces should be applicable not only to $\mathrm{CeO}_{2}$ on $\mathrm{Ge}$ by PLD, but to other material systems and physical vapor deposition techniques.

\section{ACKNOWLEDGMENTS}

This research was sponsored by the Office of Sciences and the Office of Power Technology, U.S. Department of Energy under contract No. DE-AC05-960R22464 with Lockheed Martin Energy Research Corp. 


\section{REFERENCES:}

1. D. P. Norton, A. Goyal, J. D. Budai, D. K. Christen, D. M. Kroeger, E. D. Specht, Q. He, B. Saffian, M. Paranthaman, C. E. Klabunde, D. F. Lee, B. C. Sales, and F. A. List, Science 274, 755 (1996); A. Goyal, D. P. Norton, J. D. Budai, M. Paranthaman, E. D. Specht, D. M. Kroeger, D. K. Christen, Q. He, B. Saffian, F. A. List, D. F. Lee, P. M. Martin, C. E. Klabunde, E. Hartfield, and V. K. Sikka, Appl. Phys. Lett. 69, 1795 (1996).

2. M. Paranthaman, D. F. Lee, A. Goyal. E. D. Specht. P. M. Martin, X. Cui, J. E. Mathis, R. Feenstra, D. K. Christen, and D. M. Kroeger, Supercond. Sci. \& Tech. 12, 319 (1999).

3. C. Park, D. P. Norton, D. F. Lee, J. D. Budai, D. K. Christen, D. Verebelyi, R. Feenstra, A. Goyal, M. Paranthaman, and D. M. Kroeger, Appl. Phys. Lett. 73, 1904 (1998).

4. D. P. Norton, C. Park, B. Saffian, J. D. Budai, A. Goyal, D. K. Christen, D. M. Kroeger, D. Lee, Q. He, and M. Paranthaman, Materials Research Society Symp. Proc. Vol, 474, (Materials Research Society, Pittsburg, 1997), pp. $401-406$.

5. P. Spielbuchler and G. Gritzner, J. Mater. Sci. Lett. 11, 1426 (1992).

6. G. N. Morscher, P. Pirouz, and A. H. Heuer, J. Am. Ceram. Soc. 74, 491 (1991).

7. S. Maschio, O. Sbaizero, and S. Meriani, J. Euro. Ceram. Soc. 9, 127 (1992).

8. H. Makita, S. Hanada, and O. Izumi, Acta Metall. 36, 403 (1988).

9. T. B. Reed, "Free Energy of Formation of Binary Compounds," (MIT Press, Cambridge, MA, 1971)

10. S. K. Ghandhi, "VLSI Fabrication Principles: Silicon and Gallium Arsenide," John Wiley \& Sons, New York, 1983.

11. E. H. Nicollian and J. R. Brews, "MOS (Metal Oxide Semiconductors) Physics and Technology," John Wiley \& Sons, New York, 1982.

12. K. M. Horn, E. Chason, J. Y. Tsao, J. A. Floro, S. T. Picraux, Surface Science 320, 174-184 (1994).

13. L. Surnev and M. Tikhov, Surface Science 123, 505-518 (1982).

14. R. A. McKee, F. J. Walker, and M. F. Chisholm, Phys. Rev. Lett. 81, 3014 (1998).

15. M. Paranthaman, A. Goyal, F. A. List, E. D. Specht, D. F. Lee, P. M. Martin, Q. He, D. K. Christen, D. P. Norton, J. D. Budai, and D. M. Kroeger, Physica C 275, 266 (1997).

16. S. H. Jang, D. Jung, and Y. Roh, J. Vac. Sci. Technol. B 16, 1098 (1998).

17. H. Koinuma, J. Nagata, T. Tsukahara, S. Gonda, and M. Yoshimoto, Appl. Phys. Lett. 58, 2027 (1991).

18. T. Inoue, T. Ohsuna, L. Luo, X. D. Wu, C. J. Maggiore, Y. Yamamoto, Y. Sakurai, and J. H. Chang, Appl. Phys. Lett. 59, 3604 (1991).

19. P. W. Atkins, "Physical Chemistry", (Oxford University Press, Oxford, 1982)

20. K. J. Hubbard and D. G. Schlom, J. Mater. Res. 11, 2757-2776 (1996).

*Correspondence: Email: ntn@ornl.gov, Telephone: 865 574 5965; FAX: 8655763676 